\title{
Phenotypic changes in acute myeloid leukaemia: implications in the detection of minimal residual disease
}

\author{
A Macedo, J F San Miguel, M B Vidriales, M C López-Berges, M A García-Marcos, \\ M Gonzalez, C Landolfi, A Orfão
}

\begin{abstract}
Aim-To explore the role of phenotypic changes as possible limiting factors in the immunological detection of minimal residual disease in patients with acute myeloid leukaemia (AML).

Methods-20 relapses were evaluated, with special attention to changes in the criteria used for the definition of a phenotype as "aberrant". In all cases the same monoclonal antibody and fluorochrome were used at diagnosis and in relapse.

Results-Six out of the 16 patients showed aberrant phenotypes at diagnosis. At relapse, no changes in the aberrant phenotypes were detected in most of the patients; nevertheless, in two of the four patients with asynchronous antigen expression this aberration disappeared at relapse. At diagnosis in both cases there were already small blast cell subpopulations showing the phenotype of leukaemic cells at relapse. Ten out of the 16 cases analysed showed significant changes in the expression of at least one of the markers analysed.

Conclusions-At relapse in AML the "leukaemic phenotypes" usually remained unaltered, while other phenotypic features-not relevant for distinguishing leukaemic blast cells among normal progenitors-changed frequently; however, they were not a major limitation in the immunological detection of minimal residual disease.

(f Clin Pathol 1996;49:15-18)
\end{abstract}

Servicio de

Hematología, Hospital Clínico Universitario, Salamanca, Spain

A Macedo

J F San Miguel

$M$ B Vidriales

M C López-Berges

M A García-Marcos

M Gonzalez

C Landolfi

Servicio General de

Citometría,

Universidad de

Salamanca, Spain

A Orfáo

Correspondence to: Professor Jesús F Sa Miguel, Servicio de Hematología, Hospita Clínico Universitario, Paseo de San Vicente, 37007 Salamanca, Spain.

Accepted for publication 20 July 1995
Keywords: minimal residual disease, AML, phenotypic changes, relapse.

Current induction treatments result in a high complete remission rate $(60-80 \%)$ in patients with acute myeloid leukemia (AML). ${ }^{1}$ However, many patients will eventually relapse because of the persistence of small numbers of the original leukaemic cells which are undetectable by conventional cytomorphological techniques. This is known as minimal residual disease. Alternatively, relapses could be due to the emergence of resistant subclones which develop either as a result of chemotherapyinduced clonal selection or because of the capacity of precursor leukaemic cells to mature or differentiate into different cell lineages. ${ }^{2}$ In the case of the first hypothesis, the antigenic char- acteristics of blast cells at relapse would theoretically be identical to those present at diagnosis, while if a new leukaemic subclone is responsible for the relapse its phenotypic features would differ from that of the original malignant clone. The implications of either of these two possibilities for the detection of minimal residual disease are obvious. At present the immunological detection of minimal residual disease relies on the observation that leukocyte markers may be expressed on malignant cells in combinations that are not usually seen in normal cells. ${ }^{3-7}$ According to these "aberrant" or "leukaemic" phenotypes of blast cells at diagnosis, a "custom built" pattern is established for each patient for use during follow up. The criteria used for the assessment of a phenotype as "aberrant" include: antigenic lineage infidelity, asynchronous antigen expression, and antigen overexpression. ${ }^{8}$ However, this whole strategy for detection of minimal residual disease may prove unfruitful if phenotypic changes occur frequently. Several studies have reported the occurrence of phenotypic changes at relapse ${ }^{249-16}$; however, little attention has been paid to whether or not these changes affect the criteria used to define the "leukaemic phenotypic features". Lineage switches in relapsing leukaemia have been reported in $5-8 \%$ of acute leukaemias, ${ }^{2411-13}$ with more frequent shifts from lymphoid to myeloid lineage. Drach et $a l^{10}$ have detected only one change out of 12 relapsing leukaemias, while Campana $e t a l^{4}$ found two lineage switches in 26 relapsing acute lymphoblastic leukaemia (ALL) patients but none in eight AML patients. In the present study we explored the influence of phenotypic switches on possible limitations to the immunological detection of minimal residual disease in AML patients. In doing this, special attention was paid to changes in the criteria used for the definition of a phenotype as "aberrant". In all cases the same monoclonal antibody and fluorochrome were used at diagnosis and in relapse. Our results show that the "leukaemic phenotypes" usually remain unaltered, while other phenotypic features, not relevant for discriminating leukaemic blast cells among normal progenitors, changed frequently.

\section{Methods}

PATIENTS

Sixteen "de novo" AML patients who achieved morphological complete remission ${ }^{17}$ after 
intensive chemotherapy and relapsed later were included in the study. Two patients had two relapses and one had three; thus the total number of relapses evaluated was 20 .

All patients included in the study were treated according to the protocol of the Spanish PETHEMA group for AML which includes the combination of an anthracyclin with AraC (3/7).

The diagnosis of AML was established in all cases on the basis of both morphological and cytochemical studies according to the FAB classification. ${ }^{1819}$ The complete remission criteria proposed by Ellison et al. ${ }^{17}$ were used: presence of $<5 \%$ blast cells on the bone marrow with normalisation of the marrow cellularity and/or of haemoglobin, granulocyte, and platelet levels in the peripheral blood, as well as the patient performance status.

\section{IMMUNOPHENOTYPICAL STUDIES}

Immunophenotypical studies of leukaemic cells were done in all 16 patients; analyses were carried out at the moment of diagnosis and at relapse using the same monoclonal antibodies and fluorochrome combinations. A direct immunofluorescence technique on whole lysed blood was used, including double and triple staining with fluorescein isothiocyanate (FITC), phycoerythrin, and either PerCP or Tricolor conjugated monoclonal antibodies. The specificity of the antibodies was: CD34 (IOM34,HPCA2), CD117 (95C3), CD33 (leuM9,My9), CD13 (leuM7,My7), CD15 (leuM1), CD11b (leu15), CD14 (leuM3), glycophorin A (LICR.LON.R10/D2-10), CD61 (gpIIIa), HLA/DR (anti-HLA/DR), CD2 (leu5b), CD3 (leu4), CD4 (leu3a), CD5 (leu1), CD7 (leu9), CD10 (anti-cALLA), CD19 (leu12), CD16 (leu11c), and CD56 (leu17). In order to exclude biphenotypic leukaemias, cytoplasmic CD3 and CD22 were analysed on cells fixed with paraformaldehyde $1 \%$ in phosphate buffered saline (PBS) and permeabilised with Tween 20 in PBS $(0.5 \%$ vol/ vol) as previously reported. In addition, appropriate double staining was used in order to either confirm or exclude the reactivity of certain markers on the surface of the leukaemic cells. An isotype matched control and the CD4.FITC/CD8.PE/CD3.PerCP combination were systematically used as negative and positive controls, respectively.

\section{DATA ACQUISITION AND ANALYSIS}

Data acquisition and analysis was performed on a FACScan flow cytometer (Becton Dickinson). The LYSYS II software program (Becton Dickinson) was used for data acquisition and at least 4000 events per tube were stored. Data analysis was performed using the Paint-a-Gate Plus software (Becton Dickinson) which includes a polynomial transformation of the SSC parameter $^{20}$ facility, which allows a better definition of cell populations displaying low and intermediate light scatter features.

The adjustment and calibration of the flow cytometer, as well as the fluorescence compensation, were performed before data acquisition according to previously described methods.

\section{ABERRANT IMMUNOPHENOTYPES}

Three different types of aberrant phenotype were considered: (1) lineage infidelity (coexpression of lymphoid associated markers on myeloid blast cells); (2) asynchronous antigen expression (expression of myeloid antigens absent along normal myeloid differentiation); (3) antigen overexpression (expression of aberrantly increased molecules of antigen per cell).

\section{Results}

The individual antigenic expression at diagnosis and in relapse was compared in each case; in addition, we specifically investigated the possible changes affecting the criteria used detecting minimal residual disease ("leukaemic or aberrant phenotypes").

In all cases the morphology of blast cells (FAB classification) remained unchanged (table). Six out of the 16 AML patients studied showed an "aberrant phenotype" at diagnosis (table). Two of them coexpressed lymphoid antigens (lineage infidelity): CD7 in case 1 and CD2, CD7, and CD19 in case 2 (table). In the first case, this phenotypic criterion remained unchanged at relapse, although other antigenic changes were observed (decrease in HLA/DR and increase in CD11b expression). In the second case, in addition to the lineage infidelity, the blast cells showed asynchronous antigenic expression (CD33 + CD13- CD15+). At relapse, the first criterion remained unchanged while all the blast cells acquired the CD13 antigen. It should be noted that there was already a small population ( $3.5 \%)$ of CD13+ blast cells at diagnosis. In case 3, an overexpression of CD13 antigen was the aberrant criterion used for minimal residual disease investigation and persisted unchanged at relapse (table). Three other cases (Nos 4, 5, and 6) had an asynchronous antigenic expression: in case $4(\mathrm{CD} 117+\mathrm{CD} 15+)$ and case 5 $(\mathrm{CD} 34+\mathrm{CD} 14+\mathrm{CD} 11 \mathrm{~b}-)$ the aberration remained unchanged at relapse. In case $6,80 \%$ of blast cells lacked the CD33 antigen in the presence of CD13 but in the second and third relapses the former antigen was acquired by all cells, while the expression of CD13 was reduced. Nevertheless, there was already a subpopulation $(20 \%)$ of CD $33+\mathrm{CD} 13+$ blast cells at diagnosis (table).

The remaining 10 cases did not show an aberrant phenotype (table) so in these patients - as in the others-we evaluated the possible changes during relapse according to individual antigenic expression. Shifts from negative to positive (that is, $>20 \%+$ cells) expression of antigen or vice versa were observed in 10 cases, implying the following antigens: CD34 (case 11), HLA/DR (cases 1 and 16), CD13 (case 2), CD14 (cases 6 and 16), CD15 (cases 5, 9, and 10), CD11b (cases 1, 2, and 6), CD16 (case 14), CD4 (cases 10 and 
AML immunological phenotype at diagnosis versus relapse. Results are \% positive blast cells

\begin{tabular}{|c|c|c|c|c|c|c|c|c|c|c|c|c|c|c|c|c|c|c|c|c|}
\hline Case & $F a b$ & $C D 34$ & $C D 117$ & $\begin{array}{l}H L A / \\
D R\end{array}$ & CD33 & $C D 13$ & $C D 14$ & $C D 15$ & $C D 11 b$ & $C D 16$ & $C D 4$ & $C D 56$ & $C D 2$ & $C D 3$ & $C D 5$ & $C D 7$ & $C D 10$ & $C D 19$ & GLICO & $C D 61$ \\
\hline \multirow[t]{2}{*}{1} & M1 & 100 & & 80 & 80 & 100 & 0 & 0 & 10 & 0 & 0 & 0 & 0 & 0 & & 100 & & 0 & 0 & 0 \\
\hline & M1 & 100 & & 5 & 100 & 100 & 0 & 0 & 100 & 0 & 0 & 0 & 0 & 0 & & 100 & & 0 & 0 & 0 \\
\hline \multirow[t]{2}{*}{2} & M5a & 0 & 0 & 100 & 100 & $3 \cdot 5$ & 0 & 100 & 50 & 0 & 100 & 0 & 100 & 0 & 0 & 80 & 0 & 100 & 0 & 0 \\
\hline & M5a & 0 & 0 & 100 & 100 & 80 & 0 & 100 & 2 & 0 & 75 & 0 & 75 & 0 & 0 & 92 & 0 & 54 & 0 & 0 \\
\hline \multirow[t]{2}{*}{3} & M1 & 50 & & 60 & 100 & $100^{*}$ & 0 & 0 & 0 & 0 & 60 & 0 & 0 & 0 & & 0 & & 0 & 0 & 0 \\
\hline & M1 & 40 & & 60 & 100 & $100^{*}$ & $\mathrm{NE}$ & 0 & 0 & 0 & $\mathrm{NE}$ & 0 & 0 & 0 & & 0 & & 0 & 0 & 0 \\
\hline \multirow[t]{2}{*}{4} & M2 & 50 & 30 & 50 & 80 & 90 & 0 & 50 & 0 & & 50 & & & & & 0 & & 0 & 0 & 0 \\
\hline & M2 & 100 & 100 & 100 & 80 & 100 & 0 & 90 & 0 & 0 & 90 & 100 & 0 & 0 & 0 & 0 & 0 & 0 & 0 & 0 \\
\hline \multirow[t]{2}{*}{5} & M3 & 100 & & 0 & 100 & 100 & 100 & 80 & 0 & & 100 & & & & & 0 & & 0 & 0 & 0 \\
\hline & M3 & 100 & 80 & 0 & 100 & 100 & 100 & 15 & 0 & 0 & 100 & 0 & 0 & 0 & 0 & 0 & 0 & 0 & 0 & 0 \\
\hline \multirow[t]{4}{*}{6} & M5b & & & $\mathrm{NE}$ & 22 & 100 & 31 & 0 & 31 & 0 & 45 & & & & & 0 & & 0 & 0 & 0 \\
\hline & M5b & & & 100 & 87 & 100 & 0 & 12 & 16 & & 66 & & & & & & & & 0 & 0 \\
\hline & M5b & & & 100 & 100 & 98 & 0 & & 2 & & 15 & & & & & 0 & & & & \\
\hline & M5b & 0 & & 100 & 100 & 62 & 0 & 15 & 0 & 0 & 25 & 0 & & & & 0 & & & 0 & 0 \\
\hline \multirow[t]{2}{*}{7} & M6 & 0 & 100 & 92 & 100 & 100 & 0 & 0 & 0 & 0 & 0 & 0 & 0 & 0 & 0 & 0 & 0 & 0 & 0 & 0 \\
\hline & M6 & 0 & 100 & 55 & 100 & 100 & 0 & 0 & 0 & 0 & 0 & 0 & 0 & 0 & 0 & 0 & 0 & 0 & 0 & 0 \\
\hline \multirow[t]{3}{*}{8} & M5b & 0 & & 100 & 100 & 100 & & & & & & & & & & 0 & & 0 & 0 & 0 \\
\hline & M5b & & & 100 & 100 & 100 & 0 & & 100 & & 81 & & & & & 0 & & 0 & 14 & 11 \\
\hline & M5b & & & 100 & 100 & 100 & 0 & & & 0 & 90 & 0 & & & & & & & & \\
\hline \multirow[t]{3}{*}{9} & M3 & & & 0 & 100 & 100 & 0 & 0 & 0 & & 40 & & & & & 0 & & 0 & 0 & 0 \\
\hline & M3 & 0 & & 0 & 97 & 98 & 0 & 22 & 8 & & $\mathrm{NE}$ & & & & & 0 & & 0 & 0 & 0 \\
\hline & M3 & 0 & & 0 & 100 & 100 & 0 & 0 & 0 & 0 & 100 & 0 & 0 & & & 0 & & 0 & 0 & 0 \\
\hline \multirow[t]{2}{*}{10} & M5b & 0 & & 50 & 100 & & 0 & 8 & 22 & 0 & 12 & 1 & & & & 0 & & 0 & 0 & 0 \\
\hline & M5b & 0 & & 50 & 100 & 100 & 10 & 50 & 50 & 0 & 50 & 50 & & & & 0 & & 0 & 0 & 0 \\
\hline \multirow[t]{2}{*}{11} & M3 & 1 & & 0 & 100 & 30 & 0 & 0 & 0 & 0 & 0 & 0 & 0 & 0 & & 0 & 0 & 0 & 0 & 0 \\
\hline & M3 & 40 & 0 & 0 & 100 & 100 & 0 & 0 & 0 & 0 & 30 & 0 & 0 & 0 & 5 & 0 & 0 & 0 & 0 & 0 \\
\hline \multirow{2}{*}{12} & M4 & & & 63 & 100 & 100 & 24 & 0 & & 100 & & & & & & 0 & & 25 & 0 & 0 \\
\hline & M4 & & & 100 & 100 & 100 & 25 & 0 & 100 & 100 & & & & & & & & & & \\
\hline \multirow[t]{2}{*}{13} & M5a & & & 100 & $\mathrm{NE}$ & 100 & 0 & $\mathrm{NE}$ & 0 & & 0 & & & & & 0 & 0 & 0 & 0 & 0 \\
\hline & M5a & 100 & & 100 & NE & 100 & & $\mathrm{NE}$ & 0 & 0 & & 0 & & & & 0 & & & & \\
\hline \multirow[t]{2}{*}{14} & M5b & 13 & & 87 & 87 & 100 & NE & 88 & 100 & 60 & 100 & 56 & 0 & 0 & & 0 & & 0 & 13 & 0 \\
\hline & M5b & & & 100 & 100 & 100 & $\mathrm{NE}$ & 30 & & 0 & 100 & 0 & 0 & 0 & & 0 & & 0 & & \\
\hline \multirow[t]{2}{*}{15} & M4 & 0 & & 60 & 90 & 100 & 76 & 78 & 21 & 0 & 84 & 0 & 0 & 0 & & 0 & & 0 & 0 & 0 \\
\hline & M4 & 6 & 100 & 100 & 100 & 100 & 100 & 100 & 21 & 0 & 80 & 0 & 0 & 0 & & 0 & & 0 & 0 & 0 \\
\hline \multirow[t]{2}{*}{16} & M4 & & & 72 & 100 & 90 & 60 & 0 & 100 & & 100 & & & & & 0 & 0 & 0 & 0 & 0 \\
\hline & M4 & & & 7 & 30 & 100 & 5 & 0 & 73 & & 100 & & & & & 0 & & & 0 & $\mathrm{NE}$ \\
\hline
\end{tabular}

$\mathrm{NE}=$ not evaluable.

* Antigenic overexpression.

11), and CD56 (cases 11 and 14). Thus the phenotype remained completely unchanged only in six cases. Additional variations in the percentage of positive cells were also frequently observed (table). According to the overall phenotype of the blast cells, phenotypic changes reflected an antigenic maturation in only three cases (Nos 1, 10, and 14). In the remaining cases, changes from diagnosis to relapse either only affected one antigen or the variations were not associated with a clear maturation pattern (table).

\section{Discussion}

In recent years, changes in AML blast cell phenotype at relapse from that at diagnosis have been reported. ${ }^{24-16}$ However, to the best of our knowledge there has been no systematic study on this. As a result there is scanty information at present on the incidence of these phenotypic changes, as well as on whether they are simple or complex, whether they affect the criteria used to define aberrant phenotypes, and whether they are related to maturational changes or just have a random distribution. The mechanisms that are responsible for the phenotypic changes of AML blast cells detected at relapse are still poorly understood. Among other things, the possible effect of antiblastic drugs on cell differentiation, the production of different proteins and antigens, and the selection of certain tumour cell clones have been implicated. ${ }^{2}$ However, certain technical aspects need to be considered, since they have been shown to influence the results. These include the method of analysis, sample preparation techniques, the fluorochromes used for im- munofluorescence detection methods, and even the different reactivity of certain monoclonal antibodies included in the same cluster of differentiation (CD). In the present study all these factors were controlled; for instance, only cases where the same monoclonal antibody and fluorochrome were used at diagnosis and at relapse were included, in order to ensure that the phenotypic changes detected were not due to technical artefacts but corresponded to real changes in antigenic expression.

In this series, 10 out of the 16 cases studied showed relevant changes from negative to positive or vice versa on the expression of at least one of the markers analysed. These changes mainly related to variations in the expression of the HLA/DR, CD15, CD11b, and CD4 antigens; these data could suggest that the phenotypic changes of AML blast cells, detected at relapse, are related to maturational changes. However, a detailed analysis of the phenotypic changes observed in the present study shows that, although in some cases they were associated with maturational changes (especially towards less differentiation in the blast cells), in most cases they were not clearly related to cell differentiation, or only involved one antigen. Accordingly, other factors such as the emergence of new cell clones or the expansion at relapse of minor phenotypic subpopulations already present at diagnosis could be responsible for these later changes.

In this study it was especially attractive to analyse whether the phenotypic changes observed also affected the aberrant AML blast cell phenotypes that could be used for the detection of minimal residual disease in patients in complete remission. Six of the 16 patients 
showed aberrant phenotypes at diagnosis. At relapse, no changes in the aberrant phenotypes were detected in most of the patients; nevertheless in two of the four patients with asynchronous antigen expression, resulting from the absence of CD13 in one case and of CD33 in the other, this aberration disappeared on relapse, since the myeloid leukaemic cells acquired the antigen that was initially absent. It should be mentioned that in one of these cases the asynchronous absence of CD13 coexisted with the presence of lineage infidelity, and this later aberration remained unchanged. In addition, at diagnosis in both cases there was already a small blast cell subpopulation showing the phenotype detected in the majority of leukaemic cells on relapse.

Accordingly our results show that the "leukaemic" phenotypes usually remained unchanged, while other phenotypic features frequently changed. Nevertheless the criterion of asynchronous antigen expression may change from diagnosis to relapse with a relatively high frequency, suggesting that the use of this criterion for the detection of minimal residual disease could be unreliable and it should be evaluated on the basis of the phenotype of each blast cell population detected at diagnosis.

In summary, our study shows that phenotypic changes in AML from diagnosis to relapse do not present a major limitation for the immunological detection of minimal residual disease since, although individual antigenic changes are frequent, they do not usually affect the criteria used for the definition of a phenotype as "aberrant" or "leukaemic".

This work was partially supported by grants SAF $92 / 0041$ and SAF 94/0308 of the Comisión Interministerial de Ciencia y Tecnologia (CICYT) (Spain) and Asociacion Española Contra Tecnologia

1 Cheson BD, Cassileth PA, Head DR, Schiffer CA, Bennett $\mathrm{JM}$, Bloomfield CD, et al. Report of the National Cancer Institute - sponsored workshop on definitions of diagnosis and response in acute myeloid leukemia. $\mathrm{f}$ Clin Oncol 1990;8:813-9.

2 Stass S, Mirro J, Melvin S, Pui CH, Murphy SB, Williams D. Lineage switch in acute leukemia. Blood 1984;64 701-8.
3 Wörman B, Griesinger F, Innig G, Kolkmeyer A, Toepken $\mathrm{S}$, Grove $\mathrm{D}$, et al. Detection of residual leukaemic cells in patients with acute myeloid leukemia based on cell surface antigen expression. Sangre 1992;37:133-5.

4 Campana D, Coustan-Smith E, Janossy G. The immunologic detection of minimal residual disease in acute leukemia. Blood 1990;76:163-71.

5 Van Dongen JJM, Breit TM, Adriaansen HJ, Beishuizen A Hooijkaas $\mathrm{H}$. Detection of minimal residual disease in acute leukemia by immunological marker analysis and acute leukemia by immunological marker analysis and polyme

6 Adriaansen HJ, Jacobs BC, Kappers-Klunne MC, Hählen $\mathrm{K}$, Hooijkaas H, Van Dongen JJM. Detection of residual disease in AML patients by use of double immunological marker analysis for terminal deoxynucleotidyl transferase and myeloid markers. Leukemia 1993;7:472-81.

7 Coustan-Smith E, Behm FG, Hurwitz CA, Rivera GK, Campana D. N-Cam (CD56) expression by CD34+ malignant myeloblasts has implications for minimal residual disease detection in acute myeloid leukemia. Leuk emia 1993;7:853-8.

8 Terstappen LWMM, Safford M, Konemann S, Loken MR, Zurlutter K, Buchner T, et al. Flow cytometric charZurlutter K, Buchner T, et al. Flow cytometric characterization of acute myeloid leukemia. Part II. Phenotypic

9 Pui CH, Raimondi SC, Behm FG, Ochs J, Furman WL, Bunin NJ, et al. Shifts in blast cell phenotype and caryotype at relapse of childhood lymphoblastic leukemia. Blood 1986;68:1306-10.

10 Drach J, Drach D, Glassl H, Gattringer C, Huber H. Flow cytometric determination of atypical antigen expression in acute leukemia for the study of minimal residual disease. Cytometry 1992;13:893-901.

11 Greaves MF. Target cells, cellular phenotype and lineage fidelity in human leukemia. $\mathcal{F}$ Cell Physiol 1982;suppl 1: 113-26.

12 Ruiz-Arguelles GJ, Lobato-Mendizábal E, Marin-López A. The incidence of hybrid acute leukaemia. Leukemia Res 1988;12:707-9.

13 Drexler HG, Scott CS. Morphological and immunological aspects of leukaemia diagnosis. In: Scott CS, ed. Leukaemia cytochemistry-principles and practice. Chichester: Ellis Horwood, 1989:13-59.

14 Gómez E, San Miguel JF, González M, Orfão A, Cañizo MC, Ciudad J, et al. Cambios fenotípicos de las leucemias agudas linfoblásticas en recaída y resistentes. Sangre 1991; 36:201-4.

15 Reichle A, Volkman M, Pachmann K, Diddens $H$, Emmerich B, Rastetter J. Changes in clonal growth, immunophenotype and morphology during a follow-up immunophenotype and morphology during a follow-up study of an acute lymphoblastic leukemia. In: Buchner, Schellong, Hiddeman, Ritter, eds. Haematology and blood

16 Borella L, Casper JT, Lauer SJ. Shifts in expression of cell membrane phenotypes in childhood lymphoid malignancies at relapse. Blood 1979;54:64-70.

17 Ellison RR, Holland JF, Weil M, Jacquillat C, Boiron M, Bernard J, et al. Arabinosyl cytosine: a useful agent in the treatment of acute leukemia in adults. Blood 1968;32: 507-23.

18 Bennet JM, Catovsky D, Daniel MT, Flandrin G, Galton DAG, Gralnick HR, et al. Proposals for the classification of acute leukemias. A report of the French-AmericanBritish Cooperative Group. Br f Haematol 1976;33:451-8.

19 British Cooperative Group. Brf Haematol 1976;33:451-8. DAG, Gralnick H, et al. (FAB group): Proposed revised
criteria for the classification of AML. Ann Intern Med criteria for the clas

20 Terstappen LWMM, Mickaels RA, Dost R, Loken MR. Increased light scattering resolution facilitates multidimensional flow cytometrics analysis. Cytometry 1990;11: 506-12. 